\title{
The Role of Fabric in Frictional Properties of Phyllosilicate-Rich Tectonic Faults
}

\author{
Cristiano Collettini ${ }^{1,4}$, Telemaco Tesei $^{2}$, Fabio Trippetta ${ }^{1}$, Marco M. Scuderi ${ }^{1}$, Eliza Richardson ${ }^{3}$, Chris Marone ${ }^{1,3}$, Giacomo \\ Pozzi $^{4}$, Cecilia Viti ${ }^{5}$ \\ ${ }^{1}$ Dipartimento di Scienze della Terra, Sapienza Università di Roma ${ }^{2}$ Dipartimento di Geoscienze, Università di Padova ${ }^{3}$ Department of Geoscience, The \\ Pennsylvania State University ${ }^{4}$ Istituto Nazionale di Geofisica e Vulcanologia ${ }^{5}$ Dipartimento di Scienze Fisiche, della Terra e dell'Ambiente, Università di \\ Siena
}

\section{Corresponding Author}

Cristiano Collettini

cristiano.collettini@uniroma1.it

\section{Citation}

Collettini, C., Tesei, T., Trippetta, F., Scuderi, M.M., Richardson, E., Marone, C., Pozzi, G., Viti, C. The Role of Fabric in Frictional Properties of Phyllosilicate-Rich Tectonic Faults. J. Vis. Exp. (), e62821, doi:10.3791/62821 (2021).

\section{Date Published}

November 4, 2021

DOI

$10.3791 / 62821$

URL

jove.com/video/62821

\section{Abstract}

Many rock deformation experiments used to characterize the frictional properties of tectonic faults are performed on powdered fault rocks or on bare rock surfaces. These experiments have been fundamental to document the frictional properties of granular mineral phases and provide evidence for crustal faults characterized by high friction. However, they cannot entirely capture the frictional properties of faults rich in phyllosilicates.

Numerous studies of natural faults have documented fluid-assisted reaction softening promoting the replacement of strong minerals with phyllosilicates that are distributed into continuous foliations. To study how these foliated fabrics influence the frictional properties of faults we have: 1) collected foliated phyllosilicate-rich rocks from natural faults; 2) cut the fault rock samples to obtain solid wafers $0.8-1.2 \mathrm{~cm}$ thick and $5 \mathrm{~cm} \times 5$ $\mathrm{cm}$ in area with the foliation parallel to the $5 \times 5 \mathrm{~cm}$ face of the wafer; 3 ) performed friction tests on both solid wafers sheared in their in situ geometry and powders, obtained by crushing and sieving and therefore disrupting the foliation of the same samples; 4) recovered the samples for microstructural studies from the post experiment rock samples; and 5) performed microstructural analyses via optical microscopy, scanning and transmission electron microscopy.

Mechanical data show that the solid samples with well-developed foliation show significantly lower friction in comparison to their powdered equivalents. Micro- and nano-structural studies demonstrate that low friction results from sliding along the foliation surfaces composed of phyllosilicates. When the same rocks are powdered, frictional strength is high, because sliding is accommodated by fracturing, grain rotation, translation and associated dilation. Friction tests indicate that foliated fault rocks may have low friction even when phyllosilicates constitute only a small 
percentage of the total rock volume, implying that a significant number of crustal faults are weak.

\section{Introduction}

The overall goal of this procedure is to test the frictional properties of intact phyllosilicate-rich faults sheared in their in situ geometry and to show that their friction is significantly lower than friction obtained from experiments conducted on powders of the same material.

Numerous geological studies have documented fluid-assisted reaction softening during the long-term evolution of tectonic faults. Softening occurs by the replacement of strong minerals, like quartz, feldspar, calcite, dolomite, olivine, pyroxene, with weak phyllosilicates $1,2,3,4,5,6,7,8,9,10$. This weakening originates at the grain-scale and is mainly due to sliding, at very low friction, along the phyllosilicate foliae that act together to produce a form of lubrication. From the grain-scale, fault weakening is transmitted to the entire fault zone via the interconnectivity of the phyllosilicaterich zones ${ }^{11}$. To capture the role of frictional sliding along interconnected phyllosilicate foliae, intact solid wafers of natural fault-rock samples have been sheared in their in situ geometry during rock deformation experiments ${ }^{12,13,14}$. At the end of the experiment, microstructural studies on the tested samples have been performed to check if effectively the deformation was accommodated by frictional sliding along the phyllosilicate foliae.

In comparison with traditional friction tests performed on powdered materials obtained from crushing and sieving the fault rock, experiments on intact wafers can capture the frictional sliding along the interconnected phyllosilicate-rich layers formed by fluid assisted reaction softening. In fact, during the process of powder preparation, the crushing and sieving of the fault rock disrupts the connectivity of the phyllosilicate layers and when the material is sheared in the laboratory, the absence of continuous phyllosilicate horizons favors a deformation mainly consisting of grain crushing, rotation and translation resulting in high friction.

Experiments on solid wafers show a significantly lower friction in comparison to experiments on powdered material obtained from the same rock type, particularly when the percent of the phyllosilicates is $<40 \%{ }^{15}$. With increasing phyllosilicate abundance, a reduction in friction has been documented also for tests on powdered material, since in this case the large volume of phyllosilicates is sufficient to promote interconnectivity of the weak mineral phases through the entire experimental fault $16,17,18,19,20,21,22$. Alternatively, to simulate frictional sliding on the interconnected weak layers, other types of friction tests have been performed on powders composed of $100 \%$ weak mineral phases $23,24,25$.

Geometrical fault weakening promoted by rock fabric in deformation experiments at high temperature, and therefore representative of the ductile lithosphere, has been well known for many years ${ }^{26}$. The results obtained from the procedure presented here indicate that phyllosilicate fabric promotes fault weakening also for a large number of faults contained within the seismogenic upper crust. 


\section{Protocol}

\section{Rock sample collection}

1. In a well-exposed outcrop of a natural phyllosilicate-rich fault, select the right exposure (fault rock well preserved along a plane containing fault lineation) where to collect a representative rock sample for the experiments. Take care to select a fault rock with a foliation spacing not larger than a few millimeters. This is done to capture phyllosilicate horizons in rectangular wafers up to $1.5 \mathrm{~cm}$ thick that will be sheared during friction experiments.

2. Use a hammer and chisel to obtain a fault rock sample with an area of about $10 \mathrm{~cm} \times 10 \mathrm{~cm}$ and thickness of more than $3 \mathrm{~cm}$.

3. Mark the sense of shear on the rock sample, based on kinematic indicators observed in the field (e.g., slickensides, foliations, drag folds, etc.).

NOTE: The area of the sample can be smaller than 10 $\mathrm{cm} \times 10 \mathrm{~cm}$, but it must be larger than $5 \mathrm{~cm} \times 5 \mathrm{~cm}$ that is the dimension of the forcing blocks of the experimental apparatus.

CAUTION: The foliated rock samples are very friable and therefore after the collection it may be useful to wrap the sample with some tape or a plastic film. It is mandatory that collected samples are not altered by weathering and therefore that these rocks represent the fault rock at seismogenic depth.

\section{Sample preparation for friction experiments in the double direct shear configuration}

1. Cut the rock sample to obtain rectangular wafers that fit the forcing blocks of the rock deformation apparatus. This is usually achieved in two steps: in the first step, use a standard laboratory saw to obtain a rock sample that is slightly larger than the forcing blocks; secondly use a high precision rotary blade or a hand-grinder to shape wafers $5 \mathrm{~cm} \times 5 \mathrm{~cm}$ in area and 0.8-1.2 cm thickness (Figure 1, left). For a standard double-direct shear test, two wafers of the same rock will be required to perform a single experiment. During the cut and shaping procedure, ensure that natural phyllosilicate-rich shear planes contained in the sample are maintained parallel to the surface of the forcing blocks. This means that the foliation is parallel to the $5 \mathrm{~cm} \times 5 \mathrm{~cm}$ face of the wafer.

2. Use a disk mill to crush the remaining material from the cut of the intact samples and sieve the material to obtain powders with a grain size $<125 \mu \mathrm{m}$ (Figure 1, right).

3. Mount two identical wafers on stainless steel forcing blocks with nominal frictional contact area of $5 \mathrm{~cm} \times$ $5 \mathrm{~cm}$ and then assemble them with the central forcing block to compose the symmetric double direct shear configuration.

NOTE: It is important that the shear sense imposed by the machine on the sample coincides with the natural sense of shear recorded on the wafer and marked at point 1.3.

4. Use the powders to construct two identical rock layers with thickness of about $5 \mathrm{~mm}$ and area of $5 \mathrm{~cm} \times 5 \mathrm{~cm}^{2}$. For these powdered rock samples, the natural foliation is destroyed by the sample preparing procedure with a diskmill. Use a precise leveling jig to obtain a uniform and reproducible rock layer composed of powdered material. Compose the symmetric double direct shear assembly. 


\section{Friction experiments}

1. In a biaxial apparatus ${ }^{27,28}$ use the horizontal servocontrolled hydraulic piston to apply and maintain a constant normal stress to the rock sample.

2. Apply shear stress at constant displacement rate, usually $10 \mu \mathrm{m} / \mathrm{s}$, via the vertical servo- controlled hydraulic piston.

NOTE: Loads are measured via two strain gauge load cells (accuracy $0.03 \mathrm{kN}$ ) positioned between the ram and the sample assembly. Horizontal and vertical displacements are measured by LVDT (linear variable differential transducers), with an accuracy of $0.1 \mu \mathrm{m}$, referenced at the load frame and the upper side of the $\operatorname{ram}^{27,28}$.

3. Characterize all experiments by an initial strain hardening, where the shear stress increases rapidly during elastic loading, before a yield point, followed by shear at a steady-state value of frictional stress.

\section{Post-experimental sample collection}

1. At the end of the friction test, carefully extract the experimental fault. Rubber bands or adhesive tape can be applied to the sample before load removal to maintain the integrity of the deformed rocks.

2. Impregnate with epoxy resin the rock samples. If possible for powder experiments, avoid vacuum impregnation to prevent damage to the original microstructure by the forced flow of the resin into the sample.

3. Cut these rock samples parallel to the experimental shear direction. There are several ways to track the experimental shear direction. In our double direct shear configuration, the surfaces of the steel sliding blocks in contact with gouge layers are machined with grooves $0.8 \mathrm{~mm}$ high and spaced $1 \mathrm{~mm}$ to avoid slip at the interface between gouges and steel and to ensure shear deformation within the gouges, therefore in our experiments the shear direction is perpendicular to grooves.

4. Build thin sections from the cuts for microstructural studies.

\section{Microstructural analysis}

1. Investigate with an optical microscope to characterize the bulk fault zone microstructure.

2. Use a scanning electron microscope (SEM) to investigate the main deformation processes.

3. Use a transmission electron microscope (TEM) to obtain details on the deformation processes at the nanoscale. Details on how to perform microstructural analysis can be found in previous publications $4,5,6,7,8,9,10,29$.

\section{Representative Results}

In a diagram of normal stress vs. shear stress both solid foliated and powdered samples plot along a line consistent with a brittle failure envelope, but the solid wafers have friction values significantly lower than their powdered analogues ${ }^{30}$. For example, in the specific case of a talc-rich foliation, foliated fault rocks at each normal stress have a friction coefficient that is 0.2-0.3 lower than the powders made from them (Figure 2 and ${ }^{12}$ ). The lower friction is explained by microstructural studies of the tested rocks showing that the sliding surfaces of the foliated solid wafers occur along the pre-existing phyllosilicate-rich foliation. TEM images show that slip is mainly accommodated by (001) easy sliding associated with interlayer delamination. In contrast, 
experimental microstructures from the powdered material show that significant deformation is accommodated by grainsize reduction and localization.

Although the foliated wafers of intact fault rocks and their powders have identical mineralogical compositions, the foliated samples show friction that is significantly lower than their powdered analogues. Microstructural studies indicate that the lower friction (i.e., fault weakness) of the foliated fault rocks is due to the reactivation of the pre-existing natural phyllosilicate-rich surfaces that are absent in the powdered samples since the sample preparation steps $(2.2$ - 2.4) disrupt them.
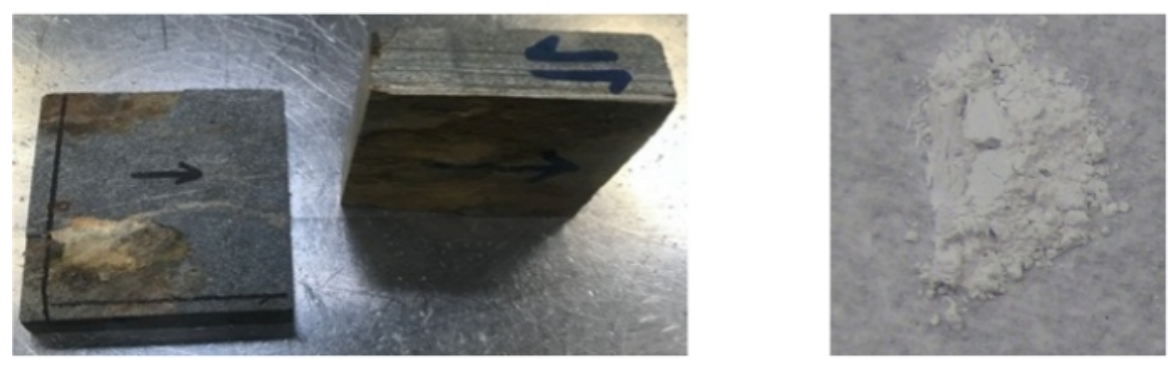

Figure 1: Representative images of the tested fault rocks: solid foliated vs. powdered material. (left) Solid foliated samples sheared parallel to the natural foliation marked by the arrows. (right) Powders obtained by crushing and sieving the solid foliated rock. Please click here to view a larger version of this figure. 


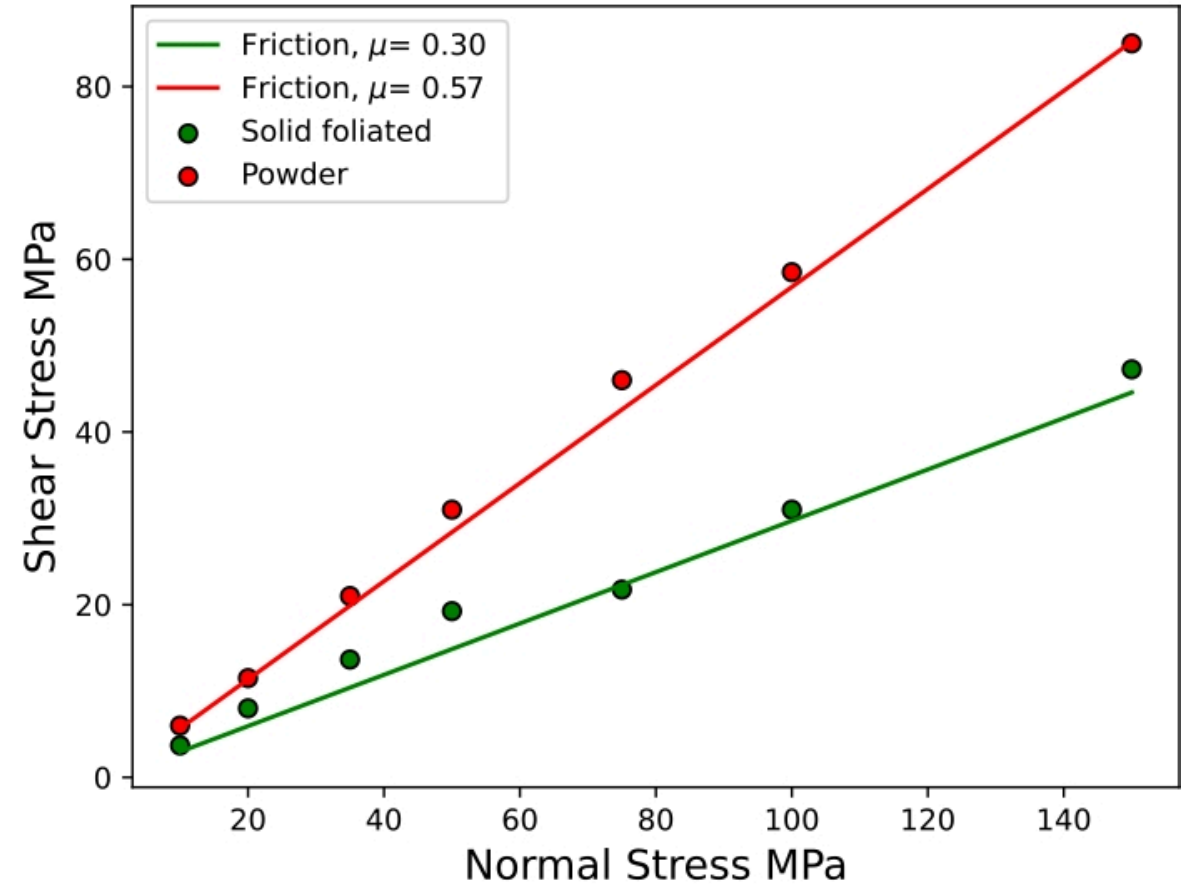

Figure 2: Friction tests on the same material (talc-rich foliation) but solid foliated samples vs. powdered rock. Each dataset plot along a line consistent with a brittle failure envelope, but the solid foliated rocks are characterized by friction significantly lower than their powdered analogue, friction, $\mu=0.3$ and $\mu=0.57$ respectively. Please click here to view a larger version of this figure.
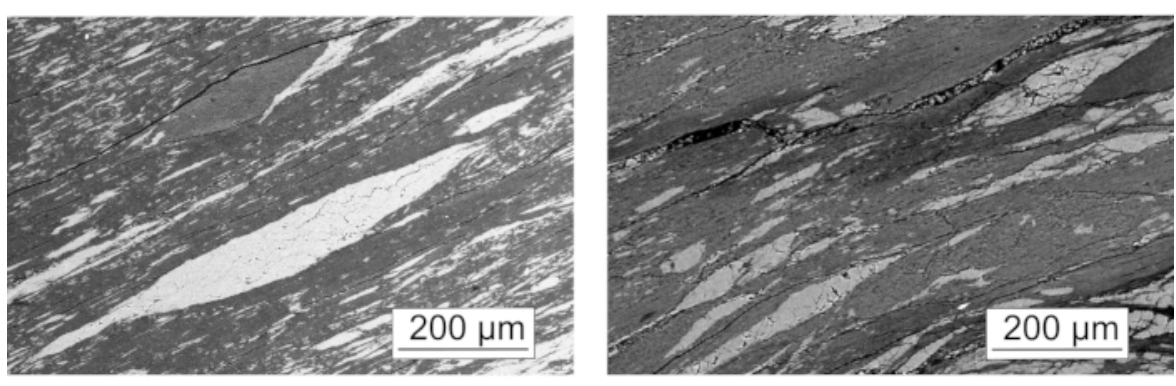

Figure 3: Natural vs. laboratory reactivated foliation. In the left picture an example of a natural talc-rich foliation with surrounding sigmoidal clasts of calcite ${ }^{31}$. The right picture shows the same foliation at the end of a friction test on wafers ${ }^{32}$. Note that during the friction test most of the slip occurs by frictional sliding along the phyllosilicate layers and that the original microstructure is preserved. Please click here to view a larger version of this figure. 


\section{Discussion}

An important point worth mentioning is that with this procedure we characterize the steady state fault frictional strength, measured with experiments at low sliding velocities (i.e., $0.01 \mu \mathrm{m} / \mathrm{s}<\mathrm{v}<100 \mu \mathrm{m} / \mathrm{s}$ ). The measured low values of friction demonstrate the weakness of phyllosilicate-rich faults resulting from long-term fluid assisted reaction softening and foliation development $1,4,5,6,7,8,9,10,11,12,30$. This low frictional strength can be used as a proxy to evaluate the fault strength at steady-state or during the pre-seismic phases of the seismic cycle. Therefore, the important dynamic weakening mechanisms that occur at high slip velocities (i.e., $>10 \mathrm{~cm} / \mathrm{s}$ ) and induced by temperature rise ${ }^{33}$ are not considered in our analysis.

The critical steps in the protocol regard the sample collection and preparation. Since phyllosilicates are characterized by very low tensile strength in the direction perpendicular to the (001) basal planes (i.e., in the direction perpendicular to the foliation), during the work with the hammer and chisel in the field or with the hand-grinder in the lab, quite often the rock samples fall apart and the shaping process has to restart. Therefore, it is strongly recommended to collect more samples than those strictly required to run experiments and arm yourself with patience.

Before integrating mechanical with microstructural data, it is important to check that the frictional sliding along the phyllosilicate-rich foliae observed along natural fault rocks is reproduced in the lab, or in other words that the natural fault rock microstructure is similar to the one obtained from shearing the wafer (Figure 3).

In experiments on solid wafers characterized by thin networks of phyllosilicates, the continuous layers of weak mineral phases can be consumed during significant shearing (displacement $>12 \mathrm{~mm}$ ). At this stage the deformation is accommodated by a combination of cataclasis of the strong mineral phases and sliding along the phyllosilicates. This coincides with a phase of strain hardening with an increase in friction of about 0.1 or more ${ }^{13}$.

The majority of rock deformation experiments, aimed at the characterization of the frictional properties of tectonic faults, are performed on millimetric rock layers that are composed by powders obtained by crushing and sieving natural fault rocks ${ }^{24,27}$ or on fault rocks that are pre-cut ${ }^{34}$. These types of experiments are fundamental to characterize the frictional properties of faults where the deformation occurs on fault gouges ${ }^{35}$ or along sharp slipping planes of localized deformation ${ }^{36}$. For faults rich in phyllosilicates, low friction and hence fault weakness is related to the interconnectivity of the phyllosilicate-rich networks, which in the field is manifested by multiple anastomosing principal slip zones. This indicate that even a small quantity of phyllosilicates can induce significant fault weakening if their interconnectivity is very high ${ }^{37,38}$. Therefore, the final goal of our laboratory experiments on solid wafers is to preserve the natural continuity of the phyllosilicate-rich layers during friction tests.

Other laboratory experiments on powdered mixtures of strong and weak mineral phases have documented fault weakening with the addition of the weak phases ${ }^{18,19,20,21,22}$. It has been observed that amounts of $40-50 \%$ of phyllosilicates induce a significant reduction in friction because during shearing they become interconnected. This suggests that for large percentages of phyllosilicates (i.e., > 40\%), experiments on wafers or powders are similar 25 .

A compilation of friction tests conducted on a large number of natural fault rocks rich in phyllosilicates, wafers or powdered material with phyllosilicates percentages $>40 \%$, under a wide 
range of experimental conditions show that friction is in the range of $0.1-0.3^{30}$. This implies that a significant number of crustal faults are weak.

\section{Disclosures}

The authors have nothing to disclose.

\section{Acknowledgments}

We kindly acknowledge Marco Albano for providing the video dealing with optical microscope and SEM and Domenico Mannetta for the rock cutting procedure. This research has been supported by the ERC Grant GLASS n 259256 and TECTONIC $n^{\circ}$ 835012. This contribution was greatly improved by the comments of three anonymous reviewers and by the editorial production suggestions on the video.

\section{References}

1. Janecke, S.U., Evans, J.P. Feldspar-influenced rock rheologies. Geology. 16, 1064-1067 (1988).

2. Handy, M.R. The solid-state flow of polymineralic rocks. Journal of Geophysical Research. 95, 8647-8661 (1990).

3. Bruhn, R., Parry, W.T.P., Yonkee, W.A., Thompson, T. Fracturing and hydrothermal alteration in normal fault zones. Pure and Applied Geophysics. 142, 609-644 (1994).

4. Evans, J.P., Chester, F.M. Fluid-rock interaction in faults of the San Andreas system: inferences from San Gabriel fault rock geochemistry and microstruc- tures. Journal of Geophysical Research. 100, 13007-13020 (1995).

5. Wintsch, R.P., Christoffersen, R., Kronenberg, A.K. Fluid-rock reaction weakening of fault zones. Journal of Geophysical Research. 100, 13021-13032 (1995).
6. Manatschal, G. Fluid- and reaction-assisted low-angle normal faulting: ev- idence from rift-related brittle fault rocks in the Alps (Err nappe, eastern Switzerland). Journal of Structural Geology. 21, 777-793 (1999).

7. Imber, J., Holdsworth, R.E., Butler, C.A., Lloyd, G.E. Fault-zone weakening pro- cesses along the reactivated Outer Hebrides Fault Zone, Scotland. Journal of the Geological Society. 154, 105-109 (1997).

8. Wibberley, C.A.J. Are feldspar-to-mica reactions necessarily reaction-softening processes in fault zones? Journal of Structural Geology. 21, 1219-1227 (1999).

9. Collettini, C., Holdsworth, R.E. Fault zone weakening processes along low- angle normal faults: insights from the Zuccale Fault, Isle of Elba, Italy. Journal of the Geological Society. 161, 1039-1051 (2004).

10. Schleicher, A.M., van der Pluijm, B., Warr, L.N. Nanocoatings of clay and creep of the San Andreas fault at Parkfield, California. Geology. 38, 667-670 (2010).

11. Holdsworth, R.E. Weak faults-rotten cores. Science. 303, 181-182 (2004).

12. Collettini, C., Niemeijer, A., Viti, C., Marone, C.J. Fault zone fabric and fault weakness. Nature. 462, 907-910 (2009).

13. Tesei, T., Collettini, C., Barchi, M.R., Carpenter, B.M., Di Stefano, G. Heterogeneous strength and fault zone complexity of carbonate-bearing thrusts with possible implications for seismicity. Earth and Planetary Science Letters. 408, 307-318 (2014).

14. Tesei, T., Lacroix, B., Collettini, C. Fault strength in thin-skinned tectonic wedges across the smectite-illite transition: constraints from friction experiments and critical tapers. Geology. 10.1130/G36978.1 (2015). 
15. Tesei, T., Collettini, C., Carpenter, B.M., Viti, C., Marone, C. Frictional strength and healing behavior of phyllosilicate-rich faults. JGR Solid Earth. 117, B09402 (2012).

16. Logan, J.M., Rauenzahn, K.A. Frictional dependence of gouge mixtures of quartz and montmorillonite on velocity, composition and fabric. Tectonophysics. 144, 87-108 (1987).

17. Saffer, D.M., Marone, C. Comparison of smectite- and illite-rich gouge fric- tional properties: application to the updip limit of the seismogenic zone along subduction megathrusts. Earth and Planetary Science Letters. 215, 219-235 (2003).

18. Moore, D.E., Lockner, D.A. Crystallographic control of the frictional behavior of dry and water-saturated sheet structure minerals. Journal of Geophysical Research. 109 (2004).

19. Takahashi, M., Mizoguchi, K., Kitamura, K., Masuda, K. Effects of clay con- tent on the frictional strength and fluid transport property of faults. Journal of Geophysical Research. 112, B08206 (2007).

20. Crawford, B.R., Faulkner, D.R., Rutter, E.H. Strength, porosity, and permeability development during hydrostatic and shear loading of synthetic quartz-clay fault gouge. Journal of Geophysical Research. 113, B03207 (2008).

21. Giorgetti, C., Carpenter, B.M., Collettini, C. Frictional behavior of talc- calcite mixtures. Journal of Geophysical Research., Solid Earth. 120 (2015).

22. Ruggeri, R. et al. The role of shale content and porewater saturation on frictional properties of simulated carbonate faults. Tectonophysics. 807 (2021).
23. Byerlee, J. Friction of rocks. Pure and Applied Geophysics. 116, 615-626 (1978).

24. Lockner, D.A., Morrow, C., Moore, D., Hickman, S. Low strength of deep San Andreas fault gouge from SAFOD core. Nature. 472, 82-86 (2011).

25. Tesei, T., Harbord, C.W.A., De Paola, N., Collettini, C., Viti, C. Friction of min- eralogically controlled serpentinites and implications for fault weakness. JGR Solid Earth. 123 (2018).

26. Shea, W.T.J., Kronenberg, A.K. Strength and anisotropy of foliated rocks with varied mica contents. Journal of Structural Geology. 15, 1097-1121 (1993).

27. Marone, C. The effect of loading rate on static friction and the rate of fault healing during the earthquake cycle. Nature. 391, 69-72, doi.org/10.1038/ 34157 (1998).

28. Collettini, C. et al. BRAVA: a novel Brittle Rock deformAtion Versatile Apparatus. International Journal of Rock Mechanics and Mining Sciences. 66, 114-123 (2014).

29. Scuderi M.M., Collettini, C., Viti C., Tinti E., Marone, C. Evolution of Shear Fabric in Granular Fault Gouge From Stable Sliding to Stick-Slip and Implications for Fault Slip Mode. Geology. 10.1130/G39033.1 (2017).

30. Collettini, C., Tesei, T., Scuderi, M.M., Carpenter, B.M., Viti, C. Beyond Byerlee friction, weak faults and implications for slip behavior. Earth and Planetary Science Letters. 519, 245-263 (2019).

31. Viti, C., Collettini, C. Growth and deformation mechanisms of talc along a natural fault: a micro/ nanostructural investigation. Contributions to Mineralogy and Petrology. 158, 529-542, ISSN: 0010-7999 (2009). 
32. Collettini, C., Niemeijer, A., Viti, C., Smith, S.A.F., Marone, C.J. Fault structure, frictional properties and mixed-mode fault slip behavior. EPSL. 311, 316-327 (2011).

33. Di Toro, G. et al. Fault lubrication during earthquakes. Nature. 471 (7339), 494-498 (2011).

34. Dieterich, J.H. Modeling of rock friction 1. Experimental results and constitutive equations. JGR Solid Earth. 84, 2161-2168 (1979).

35. Sibson, R. Fault rocks and fault mechanisms. Journal of the Geological Society. 133, 191-213 (1977).

36. Brodsky, E.E., Gilchrist, J.J., Sagy, A., Collettini, C. Faults smooth gradually as a function of slip. Earth and Planetary Science Letters. 302, 185-193 (2011).

37. Niemeijer, A.R., Marone, C., Elsworth, D. Fabric induced weakness of tectonic faults. Geophysical Research Letters. 37, L03304 (2010).

38. Lu, Z, He, C. Friction of foliated fault gouge with a biotite interlayer at hydrothermal conditions. Tectonophysics. 72-92 (2018). 